\title{
Green energy harvesting from human footsteps
}

\author{
Putri Berlian Abadi ${ }^{1}$, Denny Darlis ${ }^{2, *}$, and Mas Sarwoko Suraatmadja ${ }^{1}$ \\ ${ }^{1}$ Telkom University, School of Electrical Engineering, Jl. Telekomunikasi, Bandung, Indonesia \\ ${ }^{2}$ Telkom University, Diploma of Telecommunication Engineering, Jl. Telekomunikasi, Bandung, Indonesia
}

\begin{abstract}
The need for a sustainable green energy is increasing, while the availability of energy itself is not comparable to the needs. One of the most rapid activities in human life is footstepping. The large amounts of kinetic energy in term of pressure force are generated in every footstep activities at the crosswalk space, lecture building, office, shopping centre or market area. As an alternative energy that still has not been exploited, these human steps can be used to power some low voltage loads. In this study, a tile constructed with some piezoelectric transducers are designed and implemented to generate electrical pulses and harvesting human feet step energies. The piezoelectric transducers used in this study is Lead Zirconate Titanate type. From the pizoelectric floor energy harvester system, a tile consists of 20 pieces parallel connected piezoelectric transducer can produce AC voltage up to $71.20 \mathrm{~V}$. While the average generated voltage is $63.98 \mathrm{~V}$. So the average power is 0.0604 watt/10 footsteps. We conclude that this piezoelectric generator can be generated more power when arranged with some tiles arrangement, so we can harvest this energy efficiently.
\end{abstract}

\section{Introduction}

A sustainable green energy needs is increasing. Meanwhile the energy itself is not always available compare to the needs according to its sources. According to Ministry of Energy and Mineral Resources data on their twitter account by April 7th 2018, as shown on Fig.1, consumable electricity reached around 1,128 $\mathrm{KWh} /$ Capita as per 2018. Meanwhile, the use of renewable energy source still as low as $12,15 \%$ compare to fuel and fossil sources. This will increase as many electric appliances usage keep grow exponentially.

\section{BAURAN ENERGI PRIMER PEMBANGKIT LISTRIK 2017}
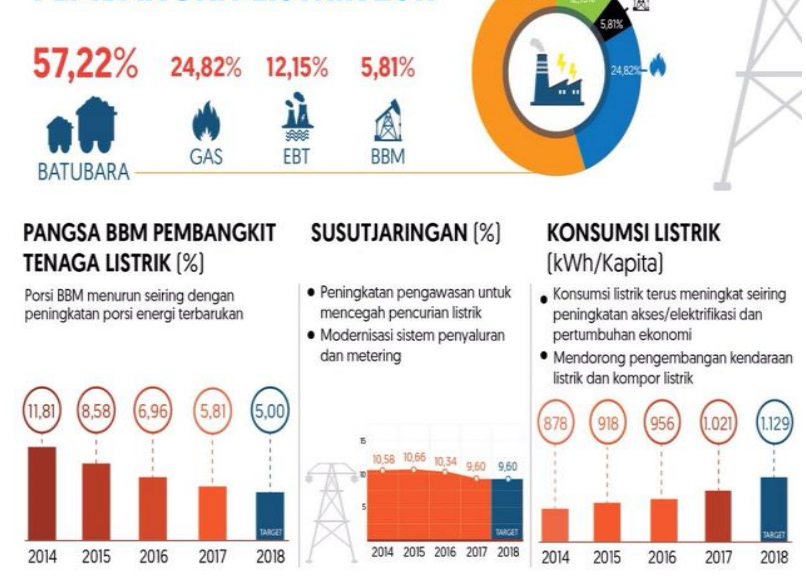

Fig. 1. Primary energy mix data from Indonesia Ministry of Energy and Mineral Resources.
One of the most rapid activities in normal human life is footstepping. Either walking, jogging, running or dancing footsteps activities needs a lot of energy and residues into body heat or sweats as shown on Fig.2. This potential waste energy can be recycle into another form of usable energy.

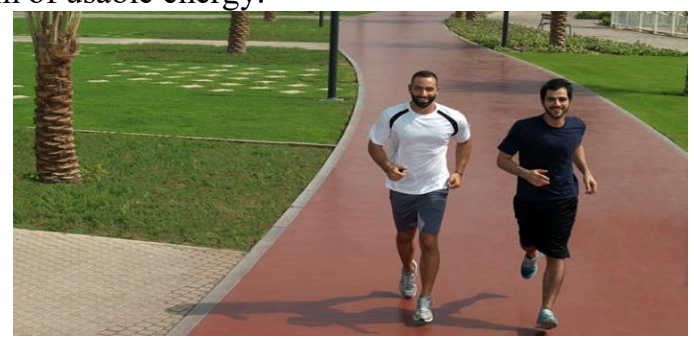

Fig. 2. Example of rubber floor jogging track (source: giovanni-photography.com).

Piezoelectric floors generate many microwatts up to many watts per step, depending on pedestrians's frequency and piezoelectric technology. Several feasibility studies has been proposed by [1][2], such as high pedestrian public space and low pedestrian private space. Another report that is [3] shows that piezoelectric pavement can also be design for intelligent road and all kind of information board, light, etc. All of this possibility begin with scavenging the human activities [4][5].

Another application of piezoelectric energy harvester found in [6][7]-[9]. The idea still using piezoelectricity phenomenon when it got pressed or vibrated by raindrops, vibration, pavement pressure, highway pressure etc.

\footnotetext{
* Corresponding author: denny.darlis@tass.telkomuniversity.ac.id
} 
In this study, an energy harvesting system utilizing human footsteps activities was designed and built utilizing the principle of piezoelectric tranducer. The transducers are placed under rubber track floor connected in series and parallel to generate voltages when pressed by human footstep activity [7]-[9].

\section{System design}

To realize the energy harvester system, a complete prototype was designed with block diagram as shown on
Fig. 3. A tile consists of rubber mat, acrylic, and piezoelectric transducers were designed as shown on Fig. 4. The tile was designed with standard $30 \mathrm{~cm} \mathrm{x} 30 \mathrm{~cm}$ size. Acrylic plates was placed to ensure uniform pressure distribution along the tile.The piezoelectric transducer was connected in parallel and series to a PCB plates surrounding the tile. At the end of of connection pair of wires are wired to rectifier circuit so as storage capacitor. Then low power load such as LEDs are used to proof that the system work.
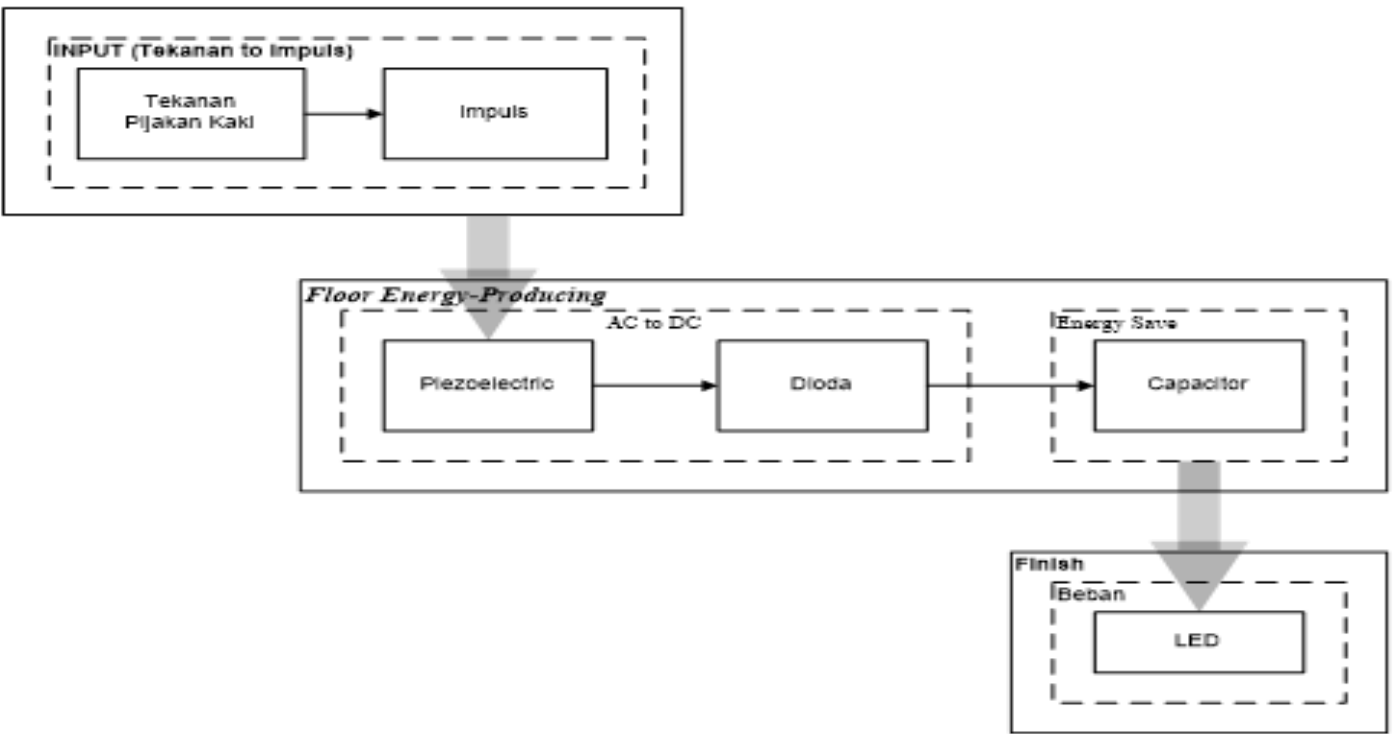

Fig. 3. Piezoelectric tile energy harvester block diagram.

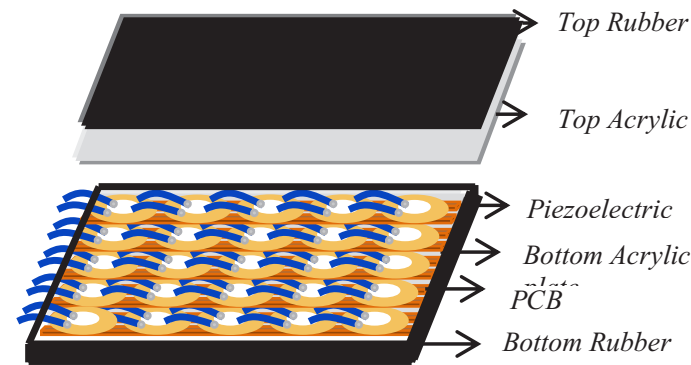

Fig. 4. Piezoelectric Tile prototype.

The output voltage generated by a disc type piezoelectric transducer can be expressed as [10]:

$$
V=(g 33 l F) /\left(\pi r^{2}\right)
$$

With V is Piezo output voltage (Volt), 1 is piezo height or thickness $(\mathrm{m}), \mathrm{F}$ is force $(\mathrm{N}), \mathrm{g} 33$ is piezoelectric voltage constant $(\mathrm{Vm} / \mathrm{N}), \mathrm{A}$ is surface area of ceramic element $(\mathrm{m} 2), \mathrm{r}$ is radius of ceramic disc or $\operatorname{rod}(\mathrm{m})$, and $\pi$ is phi conctant of 3,14 [10].

\section{Implementation}

To test the piezoelectric tiles prototype some procedures were set by providing pressure from human weights with varying mass and different footstepping as shown on Fig.5. Variations of pressure from walking in place is made by the speed of piezo press turnover about \pm 0.45 seconds, meanwhile for running on the spot the speed of leg switch pressing piezo is \pm 0.23 seconds.

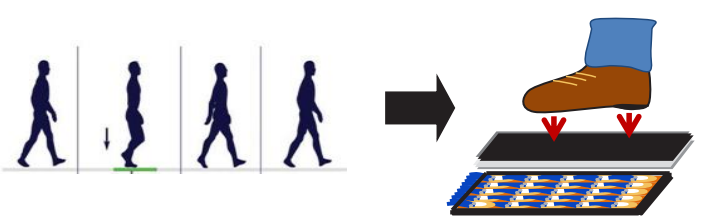

Fig. 5. Human footstepping activities on rubber floor mat prototype

The measurement of output voltages and pressures is conducted for $50 \mathrm{kgs}$ to $108 \mathrm{kgs}$ human weight when they pressing 2 pcs to 20 pcs connected piezoelectric transducers below rubber floor tile prototype as shown on Fig. 6 and 7.

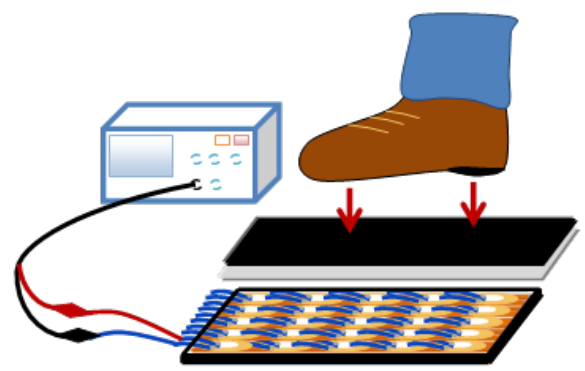

Fig. 6. Sketch of piezo floor tile testing with 20 piezoelectric transducers. 


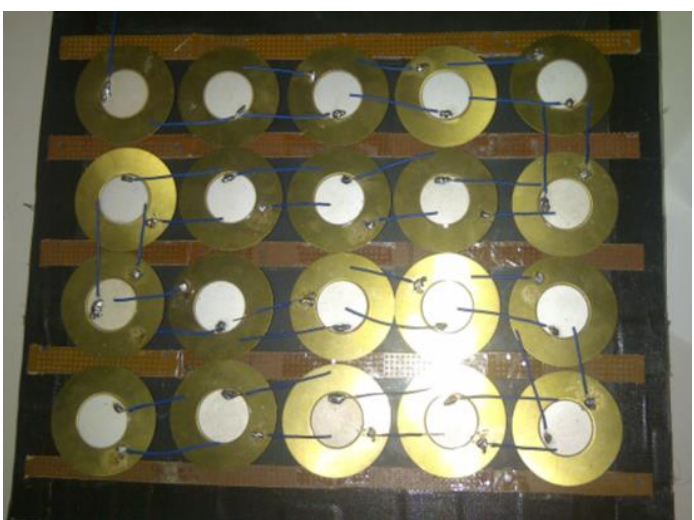

Fig. 7. Piezoelectric arrangement on prototype floor tile.

A simple power storage circuit prototype are used for storage system test as shown on Fig.8. Every footstep on the floor tile will generate power which it will be store on to the circuit.

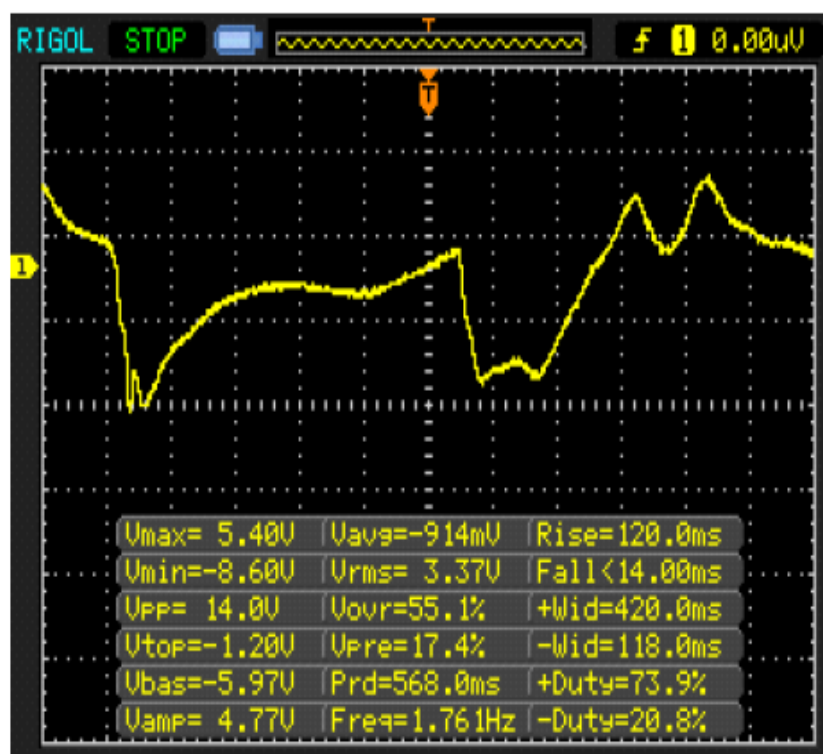

대1표 5.000

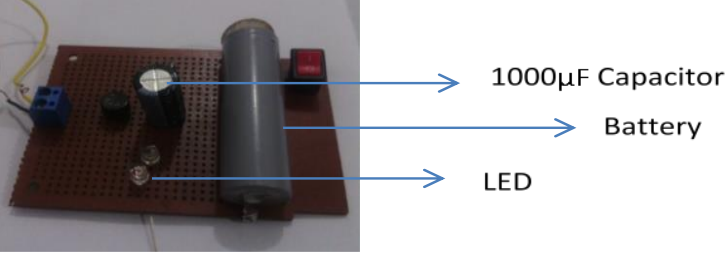

Fig. 8. Power storage circuit.

\section{Results and discussion}

An initial measurement for single piezoelectric transducer using oscilloscope showed on Fig, 9. The measurement was done for human of $60 \mathrm{kgs}$ weight running in place for 30 seconds. Random different footstepping results different maximum pulses. So is the output voltage. Next, The measurement of piezoelectric floor prototypes in this study is done by giving a footstep in the middle of $0.082 \mathrm{~m} 2$ floor area consisting of 2 until 20 pieces of piezoelectric transducers in parallel mounted below the tile as shown on Fig. 10.

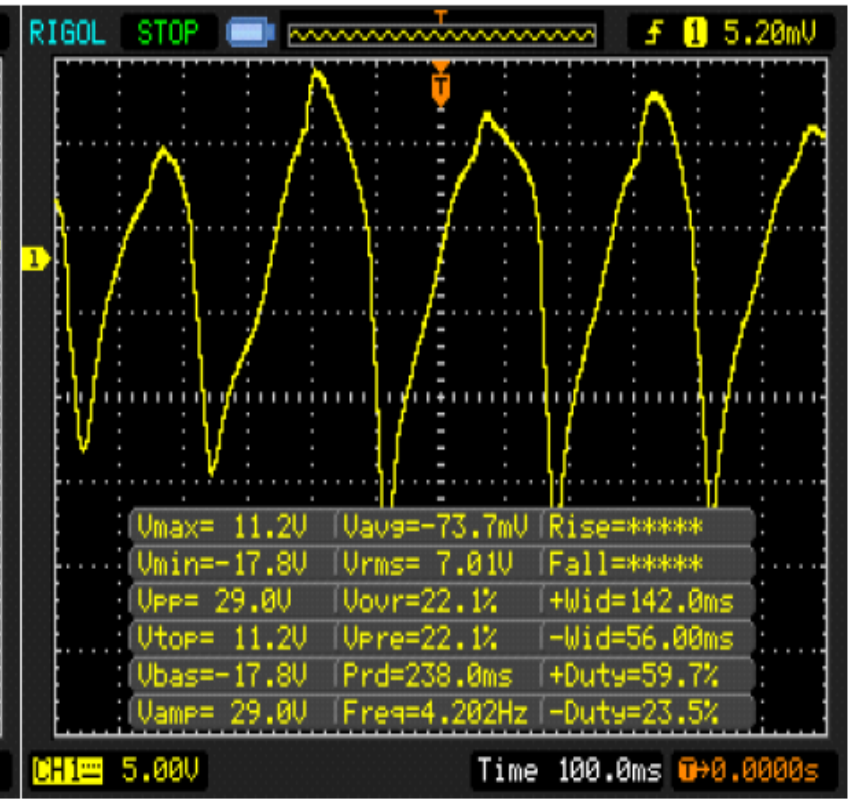

Fig. 9. The smallest output voltage signal from single piezoelectric when human of $60 \mathrm{~kg}$ weight running in place pressing floor tile prototype for 30 seconds (left) and the largest output signal voltage for same conditions (right) measured by oscilloscope.

Output Voltage of Piezoelectric Floor Tile

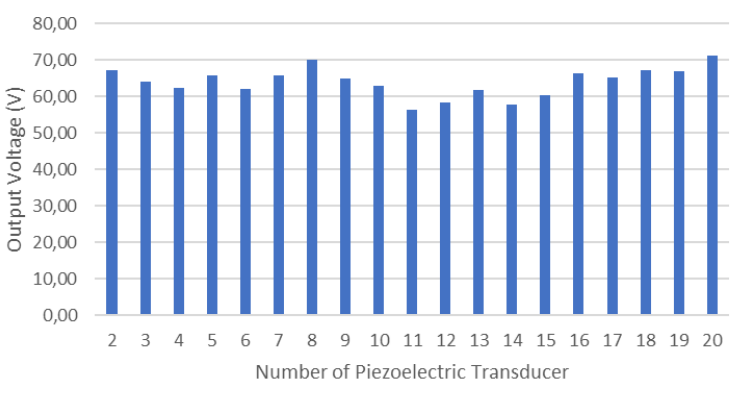

Fig. 10. Output voltage of 2 until 20 pcs piezoelectric transducer in parallel connection mounted below the floor tile prototype.
In average, the floor tile can generate output of 63,98 $\mathrm{V}$ when human of $60 \mathrm{~kg}$ weight walking in place with maximum voltage of $71.20 \mathrm{~V}$.

\section{Conclusions}

From this study we conclude piezoelectric transducer has a potential utility as green energy harvester from human footsteps by arranging it in parallel connection to generate optimal electrical energy. From the number of piezoelectric used, 2 to 20 pieces transducers can generate $\mathrm{AC}$ output pulses up to $71.20 \mathrm{~V}$ or in average of $67,20 \mathrm{~V}$ when pressed by human of $60 \mathrm{~kg}$ weight walking in place. 
Authors would like to thank School of Engineering and School of Applied Sciences, Telkom University for supporting materials and facilities in this research.

\section{References}

1. A. M. Elhalwagy, M. Y. M. Ghoneem, and M. Elhadidi, Energy Procedia, 115, (2017)

2. E. L. Worthington, M. Zhu, and P. Kirby, Piezoelectric Energy Harvesting: Enhancing Power Output by Device Optimisation and Circuit Techniques (Cranfield University, 2010)

3. X. Xu, D. Cao, H. Yang, and M. He, Int. J. Pavement Res. Technol., (2017)

4. M. H. M. Ramli, M. H. M. Yunus, C. Y. Low, and A. Jaffar, Procedia Technol., 15, (2014)

5. H. Yang, L. Wang, B. Zhou, Y. Wei, and Q. Zhao, Int. J. Pavement Res. Technol., 11, (2018)

6. E. Defiyani, P. Pangaribuan, and D. Darlis, Implementasi Papan Pengumpul Energi Tetesan Air Hujan Berbasis Piezoelektrik, (Telkom University, 2012)

7. A. Erturk and D. J. Inman, Piezoelectric Energy Harvesting. (John Wiley \& Sons, Ltd, 2011)

8. K. K. Deng and K. Andic, Piezoelectric vibration energy harvesting device, (US20050134149A1, 2005)

9. A. A. Vives and D. Soares, Piezoelectric Transducers and Applications, 2nd ed. (SpringerVerlag Berlin Heidelberg, 2008)

10. HARRIYANTO, STUDI ANALISIS GELOMBANG TEGANGAN PIEZOELEKTRIK, (Universitas Indonesia, 2013) 